\title{
Influence of Nonuniform Microstructure of SiC Ceramic Semiconductor on Its Electrical Conductivity
}

\author{
Takashi TERASHIGE and Kazuo OKANO* \\ Department of Information Systems, Fukuyama Polytechnic College, 4-8-48, Kitahonjou, Fukuyama-shi, Hiroshima 720 \\ *Department of Electrical Engineering, The Polytechnic University, 4-1-1, Hashimotodai, Sagamihara-shi, Kanagawa 229
}

\author{
$\mathrm{SiC}$ セラミック半導体の微構造不均一性の電気伝導に及ぼす影響 \\ 寺重隆視・岡野一雄* \\ 福山職業能力開発短期大学校情報システム系, 720 広島県福山市北本庄 4-8-48 \\ *職業能力開発大学校電気工学科, 229 神奈川県相模原市橋本台 4-1-1
}

\begin{abstract}
Several simulations were performed in order to estimate the effects of the nonuniformity of the SiC ceramic semiconductor microstructure on the electrical conductivity. The boundary potential model was used to express the electrical characteristics of the grain boundaries and the calculations were performed using the three-dimensional equivalent circuit in the simulations. These simulations show that the nonuniformity of the acceptor concentration or of the trap concentration at the grain boundary greatly affects the electrical conductivity of the $\mathrm{SiC}$ ceramic semiconductor. This is explained by the percolation theory. The influence of these nonuniformities should be carefully considered in order to design or to produce related devices.

[Received January 6, 1997; Accepted February 12, 1997]
\end{abstract}

Key-words : SiC, Semiconductor, Simulation, Thermistor, Microstructure, Nonuniformity, Electrical conductivity

1. Introduction

$\mathrm{SiC}$, a typical nonoxide ceramic, is a semiconductor which is stable at high temperatures, and it is expected to be used as a material for electronic devices such as the hightemperature thermistor ${ }^{1)-4}$ or the thermal battery. ${ }^{5)}$ The electrical properties of a ceramic semiconductor depend on the microstructure such as the grain size, the trap concentration at the grain boundary, the defects and the doping level in the grain.

It was already pointed out through rough calculations that such nonuniformity of the microstructure should be taken into account for the investigation of ceramic semiconductors. ${ }^{6)}$ Generally the size of the electronic devices tends to be reduced, and the effects of the nonuniformity appear clearly in the small devices. Thus more detailed investigation on the nonuniformity of the microstructure is required before $\mathrm{SiC}$ ceramics can be applied to the design and the production of related devices, especially small devices. However, it is difficult to investigate the effects of such nonuniformity experimentally because it is very hard to control the uniformity of microstructures in the sintering process.

In this study, the effects of nonuniformity on the electrical conductivity were estimated through simulations in which the acceptor concentration in the grain and the trap concentration in the grain boundary were considered as nonuniformities in the microstructure. It is pointed out that those nonuniform microstructures greatly influence the electrical conductivity of the $\mathrm{SiC}$ ceramic semiconductor, on the basis of the results of the simulations.

\section{Models and theories}

$\mathrm{SiC}$ ceramics are composed of $\mathrm{SiC}$ crystal grains and grain boundaries, as shown in Fig. 1(a), and each grain is considered to be a single-crystalline semiconductor. The grain boundary is the interface at which a grain comes into contact with another grain of different crystal orientation and at which dangling bonds exist.

Based on the results of related experiments, ${ }^{2)}$ two conditions were assumed in this simulation.
(1) The conduction of the semiconductor is p-type.

(2) The current flows in the grains and across the grain boundaries ( $I_{\mathrm{GB}}$ in Fig. 1(a)), but does not flow along the grain boundaries $\left(I_{G}=0\right.$ in Fig. $\left.1(\mathrm{a})\right)$.

Under these assumptions, the grain boundary has positive charge, because the holes in each $\mathrm{SiC}$ grain are trapped

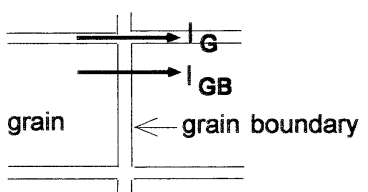

(a)

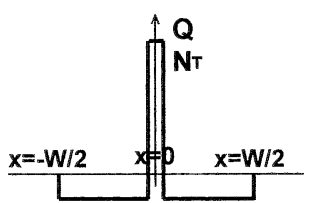

(b)

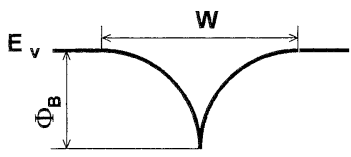

(c)

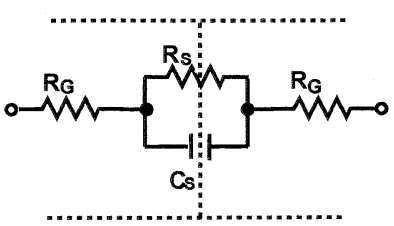

(d)

Fig. 1. Schematic models of the (a) microstructure, (b) charge distribution, (c) Schottky barrier and (d) equivalent circuit. 
by the dangling bonds in the grain boundary. As a result, negative space charges are distributed in the grain near the grain boundary because negative ionized acceptors are left there. The number of trapped holes in a grain boundary is $N_{\mathrm{T}} S$, where $N_{\mathrm{T}}$ is the trap concentration in the grain boundary and $S$ is the area of the grain boundary between two grains. The number of ionized acceptors in a grain is expressed as $N_{\mathrm{A}} W S$, where $N_{\mathrm{A}}$ is the effective acceptor concentration in the grain and $W$ is the width of the spacecharge layer. The number of holes, $N_{\mathrm{T}} S$, is equal to the number of the acceptors, $N_{\mathrm{A}} W S$, because the trapped holes in the grain boundary come from the acceptors in the grains on both sides, as shown in Fig. 1(b). Therefore the width of the space-charge layer is

$$
W=\frac{N_{\mathrm{T}}}{N_{\mathrm{A}}}
$$

An electric field is generated due to these space-charge distributions around the grain boundary, and then the Schottky barriers are formed on the both sides of the grain boundary, as shown in Fig. 1(c).

The barrier height $\Phi_{\mathrm{B}}$ is calculated as follows. First, the electric field around the grain boundary is calculated based on the charge distribution. Using Poisson's equation,

$$
\frac{\mathrm{d}^{2} \Phi_{\mathrm{B}}}{\mathrm{d} x^{2}}=\frac{e \cdot N_{\mathrm{A}}}{\varepsilon_{0} \cdot \varepsilon_{\mathrm{S}}}(0<x \leqq W / 2),
$$

where $\varepsilon_{0}$ is the dielectric constant in the vacuum and $\varepsilon_{\mathrm{S}}$ is the dielectric constant of $\mathrm{SiC}$, for which the value of 10 is used here. Equation (2) is integrated and the electric field $E$ is derived as

$$
\begin{aligned}
E & =\frac{\mathrm{d} \Phi_{\mathrm{B}}}{\mathrm{d} x}=\int_{W / 2}^{x} \frac{e \cdot N_{\mathrm{A}}}{\varepsilon_{0} \cdot \varepsilon_{\mathrm{S}}} \mathrm{d} x \\
& =\frac{e \cdot N_{\mathrm{A}}}{\varepsilon_{0} \cdot \varepsilon_{\mathrm{S}}}\left(x-\frac{W}{2}\right) .
\end{aligned}
$$

The barrier height $\Phi_{\mathrm{B}}$ is obtained by integrating of Eq. (3).

$$
\begin{aligned}
\Phi_{\mathrm{B}} & =\int_{W / 2}^{0} \frac{e \cdot N_{\mathrm{A}}}{\varepsilon_{0} \cdot \varepsilon_{\mathrm{S}}}\left(x-\frac{W}{2}\right) \mathrm{d} x \\
& =\frac{e \cdot N_{\mathrm{A}}}{2 \cdot \varepsilon_{0} \cdot \varepsilon_{\mathrm{S}}} \cdot\left(\frac{W}{2}\right)^{2}
\end{aligned}
$$

From Eq. (1) and Eq. (4), $\Phi_{\mathrm{B}}$ can also be described by

$$
\Phi_{\mathrm{B}}=\frac{e \cdot N_{\mathrm{T}}^{2}}{8 \cdot \varepsilon_{0} \varepsilon_{\mathrm{S}} N_{\mathrm{A}}} .
$$

The equivalent circuit of a grain boundary is shown in Fig. 1(d), where $R_{\mathrm{G}}$ is the resistance component in the grain, $R_{\mathrm{S}}$ is the resistance resulting from the Schottky barrier, and $C_{S}$ is the capacitance around the grain boundary resulting from the space-charge layer, which is expressed as

$$
\begin{aligned}
C_{\mathrm{S}} & =\frac{\varepsilon_{0} \varepsilon_{\mathrm{S}} S}{W} \\
& =\frac{\varepsilon_{0} \varepsilon_{\mathrm{S}} N_{\mathrm{A}}}{N_{\mathrm{T}}}
\end{aligned}
$$

from Eq. (1). $R_{\mathrm{S}}$ is

$$
R_{\mathrm{S}}=R_{0} \exp \left(\frac{e \Phi_{\mathrm{B}}}{k T}\right),
$$

where $k$ is the Boltzmann constant. The admittance of the Schottky barrier $Y_{\mathrm{S}}$ is given as

$$
Y_{\mathrm{S}}=\frac{1}{R_{\mathrm{S}}}+j 2 \pi f C_{\mathrm{S}}
$$

where $f$ is frequency.

\section{Algorithm}

In this simulation, the fluctuations of $N_{\mathrm{T}}$ and $N_{\mathrm{A}}$ were taken into account. $N_{\mathrm{T}}$ is the trap concentration in a grain boundary, and $N_{\mathrm{A}}$ is the acceptor concentration in a grain. The relationship between the parameters is shown in Fig. 2. $N_{\mathrm{T}}$ and $N_{\mathrm{A}}$ are determined so that $\log N_{\mathrm{T}}$ and $\log N_{\mathrm{A}}$ have normal distributions with the mean values of $\log N_{\mathrm{T} 0}$ and $\log N_{\mathrm{A} 0}$ and the standard deviations of $S_{\mathrm{T}}$ and $S_{\mathrm{A}}$, respectively. Through the calculation procedure shown in Fig. 2, pairs of $R_{\mathrm{S}}$ and $C_{\mathrm{S}}$ are obtained, from which $Y_{\mathrm{S}}$ can be determined using Eq. (8).

These pairs of $R_{\mathrm{S}}$ and $C_{\mathrm{S}}$ are incorporated into the 3dimensional circuit shown in Fig. 3. Each pair of $R_{\mathrm{S}}$ and $C_{\mathrm{S}}$ corresponds to a grain boundary. $R_{\mathrm{G}}$ in Fig. $1(\mathrm{~d})$ is neglected because it is considered to be very small compared to $R_{\mathrm{S}}$. The size of the sample was assumed to be $30 \mu \mathrm{m}$ in width, $30 \mu \mathrm{m}$ in length and $30 \mu \mathrm{m}$ in height. Through a related experiment,7) the average size of grains was found to be about $5 \mu \mathrm{m}$. Therefore $5 \times 5 \times 5$ ( 5 in width, 5 in length and 5 in height) pairs of $R_{\mathrm{S}}$ and $C_{\mathrm{S}}$ were taken into account in the equivalent circuit shown in Fig. 3 for the calculation. Then Kirchhoff's law is used in order to obtain the current, which is converted to the electrical conductivity.

The flow chart of the simulation process is shown in

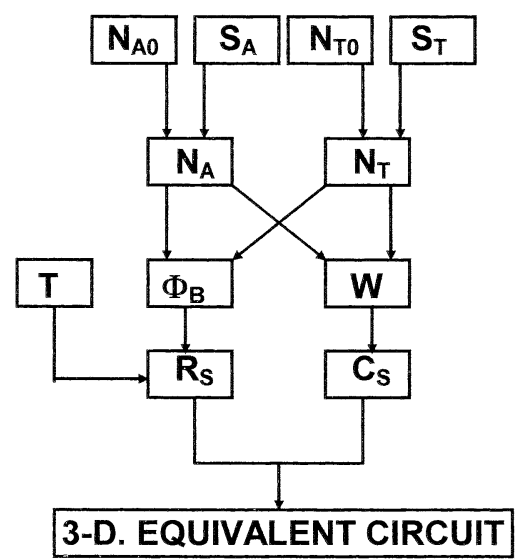

Fig. 2. Relationship between parameters used in simulation.

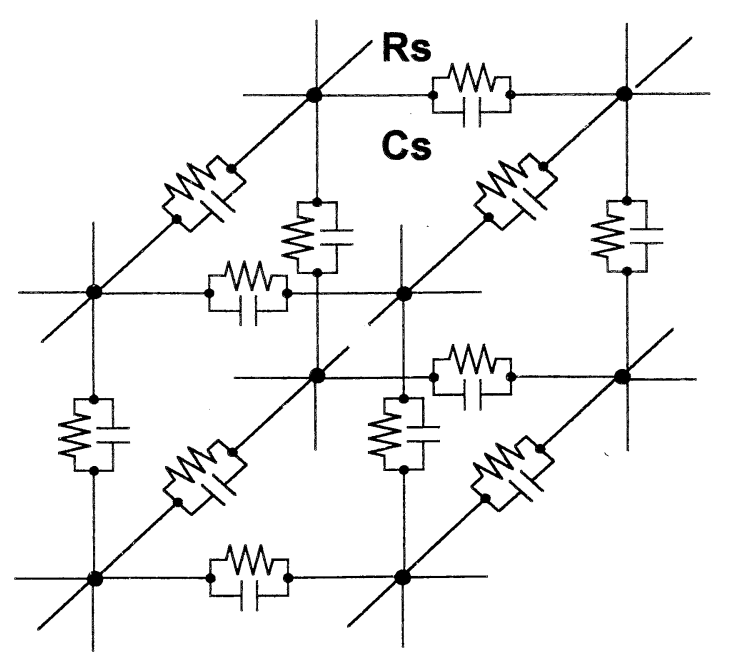

Fig. 3. Part of 3-dimensional equivalent circuit used for simulations. Each pair of $R_{\mathrm{S}}$ and $C_{\mathrm{S}}$ corresponds to a grain boundary. Pairs of $5 \times 5 \times 5$ ( 5 in width, 5 in length, 5 in height) were taken into account here. 


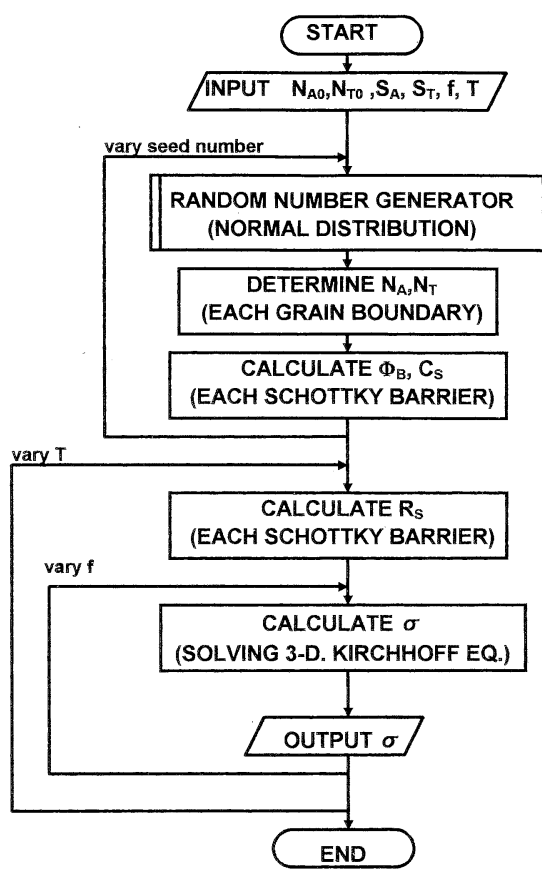

Fig. 4. Flow chart for obtaining electrical conductivity $\sigma$ of SiC ceramic semiconductor.

Fig. 4. A random number generator was used in order to determine $N_{\mathrm{T}}$ and $N_{\mathrm{A}} . f$ is the frequency of the current and $T$ is the temperature.

\section{Results and discussion}

4.1 Frequency dependence of electrical conductivity The frequency dependence of the calculated electrical conductivity is shown in Fig. 5. $S_{\mathrm{T}}$ is taken as a parameter and $S_{\mathrm{A}}$ is assumed to be zero here. The sample is assumed to have $5 \times 5 \times 5$ grain boundaries, as described in Section 3 . Each line in Fig. 5 shows the average of the calculated electrical conductivity which corresponds to respective $S_{\mathrm{T}}$. In the low-frequency (low-f) region, the frequency dependence is not observed. However, in the high-frequency (high-f) region, the electrical conductivity increases with

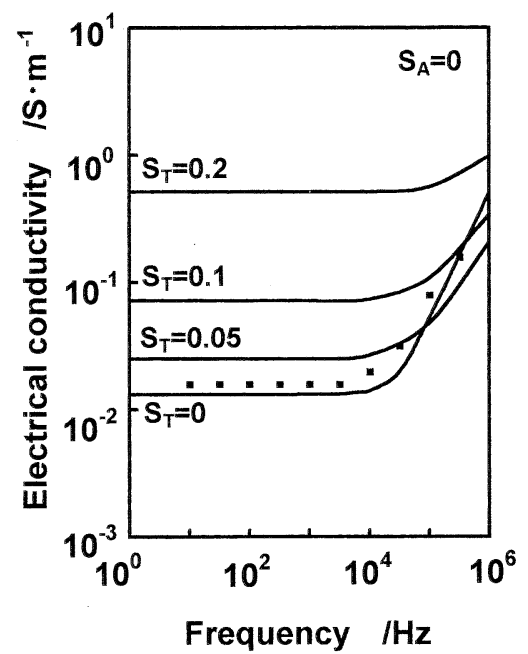

Fig. 5. Frequency dependence of electrical conductivity. Lines indicate calculated results. Calculations were done under the assumption that sample has $5 \times 5 \times 5$ grain boundaries. Plots show experimental results for a sample with $1.5 \mathrm{~mm}$ in thickness and 15 $\mathrm{mm}$ in diameter. the increase of frequency. This frequency dependence is explained by Eq. (8) which indicates that the current tends to flow through $R_{\mathrm{S}}$ in the low-f region and through $C_{\mathrm{S}}$ in the high-f region in Fig. 1(d). When $S_{\mathrm{A}}$ is used as the parameter, a similar tendency was also observed.

The measured electrical conductivity of a sample which has $1.5 \mathrm{~mm}$ in thickness and $15 \mathrm{~mm}$ in diameter is also plotted in Fig. 5. For a sample of this size, the nonuniformity of the microstructure is considered to have little effect on the electrical conductivity which approaches the value when both $S_{\mathrm{T}}$ and $S_{\mathrm{A}}$ are zero $\left(S_{\mathrm{T}}=0\right.$ in Fig. 5$)$ because there are many grain boundaries in a sample of this size and because their electrical characteristics are averaged over all the grain boundaries. The experimental and calculated values are in good agreement, which supports the validity of this simulation.

4.2 Variation of the electrical conductivity

As shown in Fig. 5, the increase of $S_{\mathrm{T}}$ tends to increase the average of the electrical conductivity in the low-f range. Figure 6 shows a histogram of calculated electrical conductivity for DC when $S_{\mathrm{T}}$ (Fig. 6(a)) and $S_{\mathrm{A}}$ (Fig. 6(b)) are taken as parameters. As shown in Fig.6, the electrical conductivity tends to increase and its variation tends to be widened as $S_{\mathrm{T}}$ or $S_{\mathrm{A}}$ increases.

These results are explained by the percolation theory ${ }^{8)-10)}$ as follows. The variation of $N_{\mathrm{T}}$ or $N_{\mathrm{A}}$ causes the variation of $R_{\mathrm{S}}$, as shown by Eq. (5) and Eq. (7). As a simplified model of the variation of $R_{\mathrm{S}}$, we consider the circuit network shown in Fig. 7, where $R_{\mathrm{S}}$ is classified into two categories, high resistance (high $R_{\mathrm{S}}$ ) and low resistance (low $R_{\mathrm{S}}$ ). There exists the possibility that the current paths are formed only with the low $R_{\mathrm{S}}$ between the electrodes. Then the electrical conductivity increases because the cur-

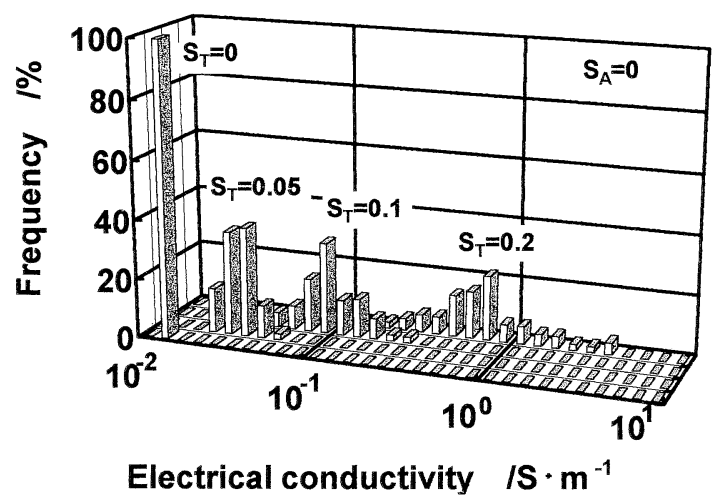

(a)

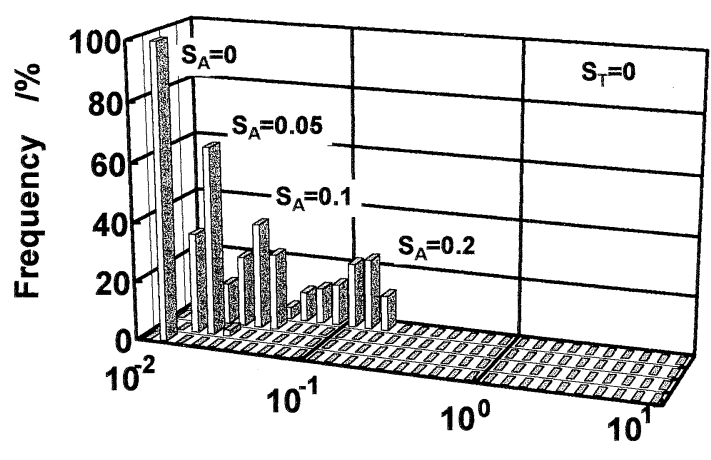

Electrical conductivity $/ \mathrm{S} \cdot \mathrm{m}^{-1}$

(b)

Fig. 6. Histogram of calculated electrical conductivity for DC. $S_{\mathrm{T}}$ (a) and $S_{\mathrm{A}}(\mathrm{b})$ are taken as parameters. 


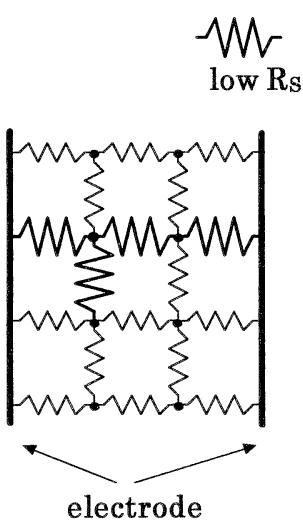

(a)

$$
\text { W }
$$

high $R_{S}$

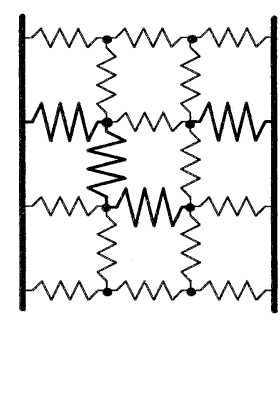

(b)
Fig. 7. Simplified model of $R_{\mathrm{S}}$ variation. Resistors drawn in bold lines have low resistance (low- $R_{\mathrm{S}}$ ) and those drawn in fine lines have high resistance (high- $R_{\mathrm{S}}$ ). Four low- $R_{\mathrm{S}}$ resistors exist in both (a) and (b). Electrodes are (a) linked and (b) not linked by low- $R_{\mathrm{S}}$ resistors.

rent tends to flow only through pathslike those shown in Fig. 7(a). This probability, which is called the percolation probability, depends on the ratio of the number of low- $R_{\mathrm{S}}$ resistors to the total number of resistors. With the increase of this ratio, the percolation probability increases. The actual situation is similar to this simplified case. The large $S_{\mathrm{T}}$ tends to cause a large variation of $R_{\mathrm{S}}$, and many of the resistors have low resistance, which then tends to make the electrical conductivity large. The dependence of electrical conductivity on $S_{\mathrm{T}}$ (Fig. 6(a)) is stronger than that on $S_{\mathrm{A}}$ (Fig. 6(b)) because the influence of $N_{\mathrm{T}}$ is greater than that of $N_{\mathrm{A}}$, as shown in Eq. (5) and Eq. (7).

4.3 Temperature dependence of electrical conductivity

The temperature dependence of the electrical conductivity is shown in Fig. 8. $S_{\mathrm{T}}$ is taken as a parameter. The lines in Fig. 8 are the average values of calculated electrical conductivity for DC. The electrical conductivity increases with the increase of $S_{\mathrm{T}}$ over the entire range of temperature. The gradient of each line decreases as $S_{\mathrm{T}}$ increases. These results also indicate that the effective height of the Schottky barrier decreases, as seen in Eq. (7), with the increase of $S_{\mathrm{T}}$. These results are also explained by the percolation theory, ${ }^{8)-10)}$ as noted in Section 4.2. The large $S_{\mathrm{T}}$ tends to make the variation of $\Phi_{\mathrm{B}}$ wide and many $\Phi_{\mathrm{B}}$ have low barrier height (low $\Phi_{\mathrm{B}}$ ). The current flows through the path, formed only by the low $\Phi_{\mathrm{B}}$, with a certain probability, and then tends to make the electrical conductivity large. These findings also mean that the sensitivity of the material when used as a thermistor decreases due to the nonuniformity of the microstructure.

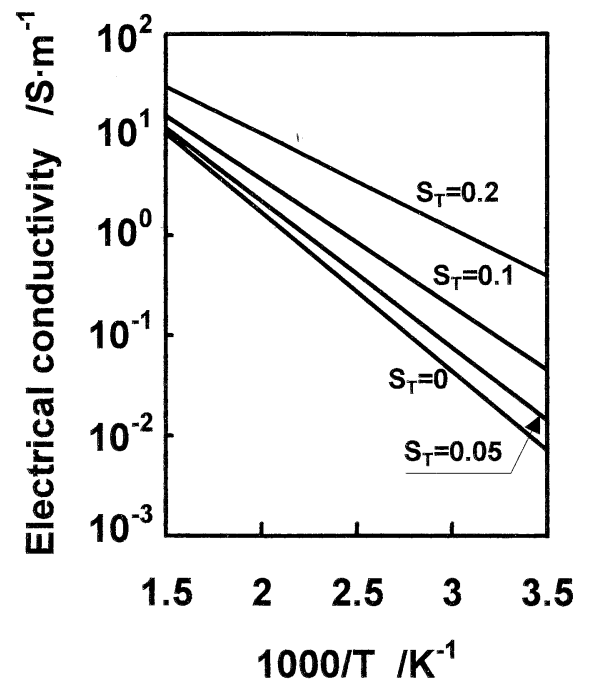

Fig. 8. Temperature dependence of electrical conductivity.

\section{Conclusions}

In order to estimate the effects of the nonuniformity of the $\mathrm{SiC}$ ceramic semiconductor microstructure on the electrical conductivity, several simulations in which $S_{\mathrm{T}}$ and $S_{\mathrm{A}}$ were used as the parameters were performed. From the results of these simulations, the following were revealed.

(1) The electrical conductivity has a frequency dependence and it shows good agreement with the measured results.

(2) Increasing $S_{\mathrm{T}}$ or $S_{\mathrm{A}}$ tends to increase the electrical conductivity itself and the width of the variation of the electrical conductivity in the low-frequency region. These tendencies were explained by the percolation theory.

(3) Increasing $S_{\mathrm{T}}$ or $S_{\mathrm{A}}$ tends to decrease the sensitivity of the material when used as a thermistor.

\section{References}

1) K. Okano, Trans. IEICE, E70, 336-38 (1987).

2) K. Okano, Yogyo-Kyokai-Shi, 94, 219-25 (1986).

3) K. Okano and A. Takahashi, Hyomen Kagaku, 8, 210-15 (1987).

4) K. Okano, K. Kurashima and Y. Kobayashi, Trans. IEE. Japan, 112-C, 819-27 (1992).

5) K. Okano, K. Fujinuma and K. Maruoka, Seramikkusu Ronbunshi, 99, 244-47 (1991).

6) K. Okano, Seramikkusu Ronbunshi, 97, 1318-20 (1989).

7) K. Okano, Seramikkusu Ronbunshi, 99, 276-81 (1991).

8) B. J. Last and D. J. Thouless, Phys. Rev. Lett., 27, 1719-21 (1971).

9) S. Kirkpatrick, Rev. Modern Phys., 45, 574-88 (1973).

10) R. B. Stinchcombe, J. Phys. C: Solid State Phys., 6, L1-5 (1973). 